\title{
VIRTUAL SURGICAL PLANNING USING STEREOLITHOGRAPHIC MODELS FOR SEGMENTAL MANDIBULAR RESECTION WITH LIMITED EXTRAORAL SKIN INCISION VERSUS TRADITIONAL SURGICAL PROTOCOLS
}

\author{
Mohammad A. Elshall*, Ibrahim M. Nowair* and Abdelfattah A. Sadakah ${ }^{* *}$
}

\begin{abstract}
Purpose: To evaluate, both clinically and radiographically the usage of stereolithographic model with limited extraoral skin incision versus the traditional method using dry mandibles in preoperative adaptation of locking reconstruction plate for lateral mandibular continuity defects in delayed type mandibular reconstruction.
\end{abstract}

Materials and methods: Sixteen patients were randomly classified into two equal groups; in which group I was the control (traditional method) and group II was the study group (new method). Group (I): 8 patients with mandibular lesions indicated for segmental mandibular resections via intraoral approach and a wide extraoral incision assisted with preoperative adaptation of the reconstruction plate on dry mandible and refined intraoperatively with the use of a plastic template. Group (II): 8 patients with mandibular lesions indicated for segmental mandibular resections via intraoral approach and with very limited extraoral incision assisted with preoperative adaptation of the reconstruction plate on the patient's stereolithographic model.

Results: The operation time, plate bending and adaptation time, the intraoperative blood loss, scar visibility, TMJ dysfunction, facial asymmetry, accurate plate adaptation, proper plate angulation, and plate over-extension especially in the proximal segment beyond the sigmoid notch, all were with statistically significant differences between both groups with better results always found in group II patients. However, no cases of tumor recurrence, plate exposure, or abnormal condylar position were recorded at the last follow up visit (6 months) in both groups.

Conclusion: The use of the patient`s 3-D steriolithographic model for virtual surgical planning for segmental mandibular resection with limited skin incision has several advantages over the traditionally used method. It improves reconstruction of form and function, decreases operating room time and complications and enhances the capability to perform more accurate surgical procedures.

KEYWORDS: Limited submandibular incision, Segmental mandibular resection, Stereolithographic model, Thread-lock reconstruction plate.

* Associate Prof of Oral \& Maxillofacial Surgery, Faculty of Dentistry, Tanta University, Egypt.

** Professor of Oral \& Maxillofacial Surgery, Faculty of Dentistry, Tanta University, Egypt. 


\section{INTRODUCTION}

The mandible is an important structure of the head and neck. It provides protection to the upper airway and supports the tongue, the lower dentition, and the muscles of the floor of the mouth. These functions of the mandible permit mastication, articulation, deglutition, and respiration. ${ }^{[1]}$ Mandibular defects may be the result of avulsive oral and maxillofacial trauma or infection. However, most often result from benign or malignant tumors ablation. ${ }^{[2]}$

Mandibular defects were classified by Jewer et al. 1989 as HCL classification, which was devised to reflect the complexity of the reconstructive problem rather than the size of the reconstruction alone. Hence " $H$ " defects are lateral defects which include the condyle, "C" defects involve the entire symphyseal area, including both lower canines, and "L" defects are lateral defects not including the condyle. ${ }^{[3]}$

Mandibular reconstruction should aim at restoring the original skeletal and soft tissue anatomy. Patient comfort and oral function are greatly dependent on successful mandibular reconstruction. This implies not only restoration of continuity defects of the jaw but also includes restoration of other factors such as speech, swallowing, chewing and facial aesthetics. ${ }^{[4]}$

Mandibular reconstruction after ablative surgery is indicated for the following reasons: to stabilize the residual segments, maintain facial contour and restore masticatory function. The first two aims may be easily satisfied with a simple metallic plate (known as reconstruction plate): however the third and most important aim can only be served by the provision of bone as a replacement of the missing mandibular segment. ${ }^{[5,6]}$

Locking reconstruction plates and screws have many advantages over other reconstruction plates; stability is attained by locking the screw to the plate. Thus, the plate may ride slightly off the mandible, while still applying rigid support. This slight bony separation also prevents disruption of the cortical bone blood supply. They have also a low incidence of complications and can offer absolute stability in the functional restoration of mandibular defects. ${ }^{[7,8]}$

Some reported researches found that delayed reconstruction of mandibular defects was favored over primary reconstruction secondary to the belief that primary reconstruction could potentially mask tumor recurrence. In addition, oral contamination of primary reconstruction resulted in an unacceptably high complication rates from infection. ${ }^{[9]}$

In cases when the tumor distorts the buccal cortex of the mandible or if the tumor margin might be violated in attempts to expose the outer cortex, the plate cannot be precontoured to the native mandible. In this situation, different techniques can be used: (1) use of temporary long miniplate, spanning the defect while resection occurs; (2) fixation of proximal mandibular segments to maxillary tuberosities with temporary supramucosal miniplates while resection occurs; (3) use of intermaxillary fixation in dentate patients with anterior segment resection; (4) use of external fixation systems ${ }^{[10,11]}$ and (5) use of virtual surgical planning. ${ }^{[12]}$

In virtual surgical planning, a mirror image of the unaffected side can be created and superimposed on the affected side and a stereolithographic model can be generated. This "hybrid" model can be used to precontour the plate intraoperatively or have a custom patient-specific plate designed and milled by the plating company. ${ }^{[12]}$

The plate is fixed to the mandible on either side of the defect using at least 3-4 bicortical screws. With the use of the locking screws, less accurate adaptation of the plate can be accepted. However, to minimize plate extrusion, the plate should abut the underling bone and minimize the dead space. Reconstruction plates are stress shielding and will insure stability of the reconstruction during the healing period and allow early function. However, this stress-shielding 
effect may cause demineralization and decrease in bone strength. ${ }^{[13]}$

Traditionally, the pre-surgical stereolithographic biomodel was made of the replica of the deformed jaw bone disfigured by the huge tumor. The surgeons have to sculpture the original model into the harmonious or symmetrical ones. With the aid of virtual method, the diseased part of the mandible can be replaced by non-diseased part by mirror imaging technique and create a symmetrical stereolithographic biomodel for surgical planning. This modified virtual method has been reported to be useful and effective in surgical reconstruction after mandibular tumor ablation and especially for the huge defect involving the midline of mandible. ${ }^{[14]}$

Baesd on the hypothesis that the use of the patient's 3-D generated steriolithographic model for preoperative adaptation of the reconstruction plate will facilitate and improve the outcomes of the surgical procedure by rapid and accurate positioning of the plate via a limited submandibular skin incision, this study was planned and conducted to compare 2 groups of patients with different surgical procedures.

The aim of this study was to compare the results of two different methods used for delayed bony reconstruction of the lateral mandibular continuity defects following tumor resection in two groups of patients. A virtual method using the patient's 3-D steriolithographic model for plate adaptation and a limited surgical skin incision was compared to the traditional reconstruction method that routinly used in our departement utilizing the dry mandibles in preoperative adaptation of the locking reconstruction plate and a wide surgical skin incision.

\section{MATERIALS AND METHODS}

This is a prospective randomized controlled clinical study that was conducted on sixteen patients suffering from presence of mandibular central benign lesions indicated for segmental mandibular resection without condylar disarticulation.

All patients were selected from the out-patient clinic of oral and maxillofacial surgery department, faculty of dentistry at Tanta university. Ethical approval of the study was obtained from the Research Ethics Committee of Faculty of Dentistry in which the research was conducted.

Selection criteria: Patients with benign lesions indicated for segmental mandibular resections and delayed bone grafting, ability to understand specific goals of the study and comprehend informed consent process, and patients without any relevant systemic disease that might interfere with soft tissue healing.

The sixteen patients were randomly classified into two equal groups; in which group I was the control (traditional method) and group II was the study group (new method): Group (I): 8 patients with mandibular lesions indicated for segmental mandibular resections via intraoral approach and a wide extraoral incision assisted with preoperative adaptation of the reconstruction plate on dry mandible and refined intraoperatively with the use of a plastic template. Group (II): 8 patients with mandibular lesions indicated for segmental mandibular resections via intraoral approach and with very limited extraoral incision assisted with preoperative adaptation of the reconstruction plate on the patient's stereolithographic model.

The clinical, histopathological and radiographical data of group I patients are illustrated in table 1 and of group II patients in table 2.

\section{Preoperative patient examination:}

\section{A-Clinically (Fig 1).}

The routne clinical examination was performed for all patients after detailed related history taking to detect lesion size, extension, cortical expansion, condition of overlying soft tissues, presence of infection, consistency, and the condition of the realted lymph nodes. 
TABLE (1) Clinical, histopathological and radiographical data of eight patients (group I).

\begin{tabular}{|c|l|l|l|l|}
\hline $\begin{array}{c}\text { Patient } \\
\text { No. }\end{array}$ & $\begin{array}{l}\text { Sex } \\
\text { M (male) } \\
\text { F (female) }\end{array}$ & $\begin{array}{l}\text { Age } \\
\text { (years) }\end{array}$ & Results of incisional biopsy. & Extension of the lesion. \\
\hline 1 & M & 30 & Ameloblastoma & Lower half of right ramus, angle to right $1^{\text {st }}$ molar. \\
\hline 2 & M & 43 & Ameloblastoma & Left angle to distal root of left $1^{\text {st }}$ molar. \\
\hline 3 & M & 38 & Ameloblastoma & Lower half of left ramus, angle to left $1^{\text {st }}$ premolar. \\
\hline 4 & M & 32 & Hybrid tumor $\left(\right.$ CEOT $^{*}$ with AOT $\left.^{\Delta}\right)$ & Left angle to left $2^{\text {nd }}$ premolar. \\
\hline 5 & M & 38 & Ossifying fibroma & Right angle to right $2^{\text {nd }}$ molar. \\
\hline 6 & F & 32 & Ameloblastoma & Right angle to right $2^{\text {nd }}$ molar. \\
\hline 7 & M & 26 & Heamangioma & Right side subsegmiod to right $2^{\text {nd }}$ premolar. \\
\hline 8 & M & 54 & Ameloblastoma & Left angle to left $2^{\text {nd }}$ molar. \\
\hline
\end{tabular}

*Calcifying Epithelial Odontogenic Tumor. ${ }^{4}$ Adenamatiod Odontogenic Tumor.

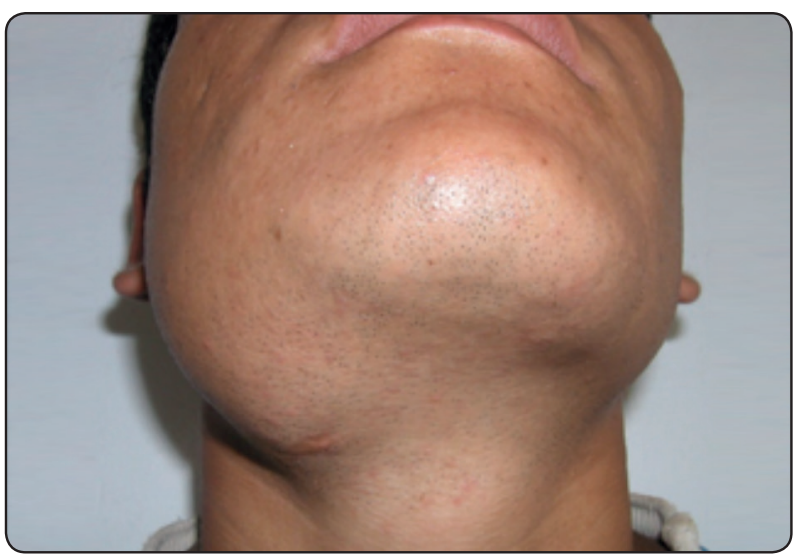

Fig. (1) Preoperative basal photograph showing patient with Ameloblastoma producing facial disfigurement and large swelling at the Rt ramus, angle and submandibular regions.

\section{B-Radiographically (Fig 2: $a, b \& c)$.}

The radiographic interpretation was focused on lesion shape and boundaries, extension, root resorption of related teeth, presence of cortical expansion and perforation and invasion to related vital structures if present. Two types of radiographs were used; panoramic radiograph (OPG) and ccomputed tomography (CT scans) in axial and coronal sections, and 3-D reformatted views.
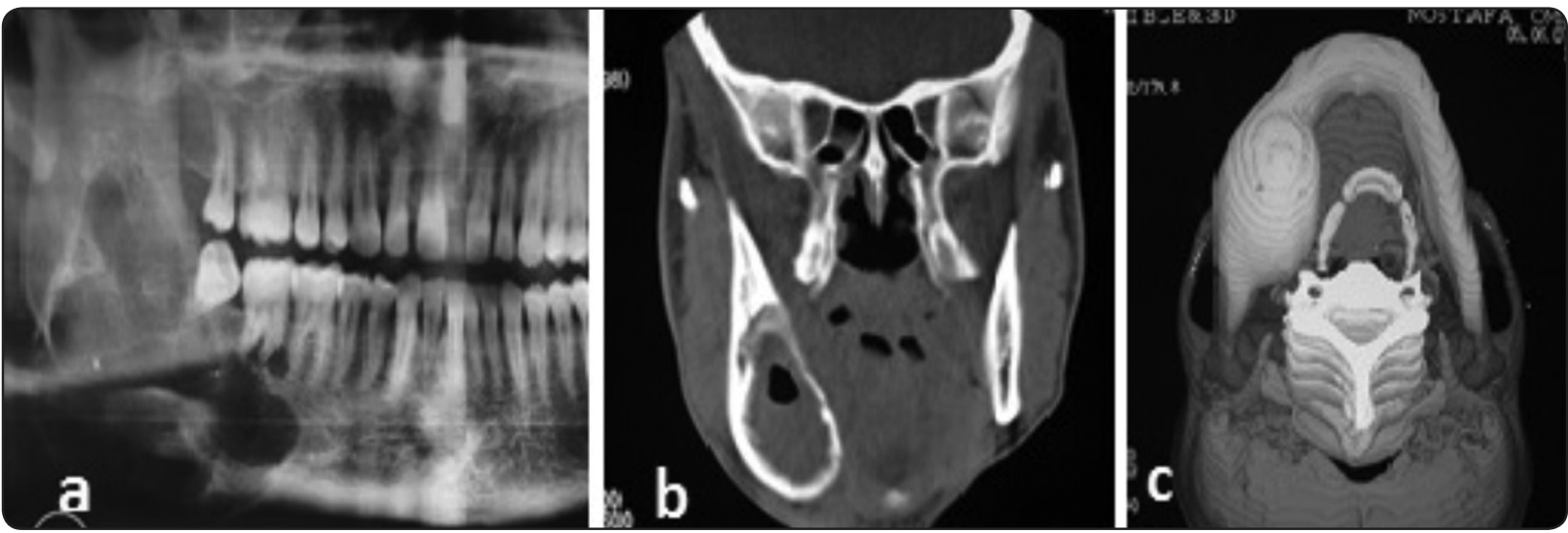

Fig. (2) Preoperative images of the same patient showing multilocular radiolucency of right side: a) OPG, b) coronal CT, c) 3-D $\mathrm{CT}$ in basal veiw. 
TABLE (2) Clinical, histopathological and radiographical data of eight patients (group II).

\begin{tabular}{|c|l|l|l|l|}
\hline $\begin{array}{c}\text { Patient } \\
\text { No. }\end{array}$ & Sex & Age & $\begin{array}{l}\text { Results of } \\
\text { incisional } \\
\text { biopsy. }\end{array}$ & $\begin{array}{l}\text { Extension of the } \\
\text { lesion. }\end{array}$ \\
\hline 1 & M & 44 & Ameloblastoma & $\begin{array}{l}\text { Left angle to left } \\
\text { lateral incisor. }\end{array}$ \\
\hline 2 & M & 50 & Ameloblastoma & $\begin{array}{l}\text { Left } 2^{\text {nd }} \text { molar to } \\
\text { left canine. }\end{array}$ \\
\hline 3 & M & 50 & Ameloblastoma & $\begin{array}{l}\text { Lower half of } \\
\text { right ramus, angle } \\
\text { to right central } \\
\text { incisor. }\end{array}$ \\
\hline 4 & M & 40 & Ameloblastoma & $\begin{array}{l}\text { Left angle to left } \\
\text { lateral incisor. }\end{array}$ \\
\hline 5 & F & 35 & Ameloblastoma & $\begin{array}{l}\text { Left } 2^{\text {nd }} \text { molar to } \\
\text { left lateral incisor. }\end{array}$ \\
\hline 6 & F & 44 & Ameloblastoma & $\begin{array}{l}\text { Right angle to right } \\
\text { lateral incisor. }\end{array}$ \\
\hline 7 & M & 31 & Ameloblastoma & $\begin{array}{l}\text { Right ramus, angle } \\
\text { to right lateral } \\
\text { incisor.. }\end{array}$ \\
\hline 8 & M & 37 & $\begin{array}{l}\text { Ossifying } \\
\text { fibroma }\end{array}$ & $\begin{array}{l}\text { Left } 3^{\text {rd }} \text { molar to } \\
\text { left } 1^{\text {st }} \text { premolar. }\end{array}$ \\
\hline
\end{tabular}

\section{MATERIALS}

The reconstruction plating system used in this study is locking reconstruction plate and screws with its adaptation, bending and installation instruments (Fig 3: a \& b).
A 3-D steriolithographic model of the patient's mandible was used in group II patients for preoperative adaptation of the reconstruction plate. Utilizing the recent technology of 3-D printing, a mirror image of the unaffected side was created and superimposed on the affected side and a stereolithographic model was created.

\section{Surgical procedure}

The surgical technique was performed in programmed steps for all patients as follow:

All patients were operated under general anesthesia which was induced by intravenous access. Intubation was routinely performed in nasoendotracheal fashion. Antibiotics and steroid drugs were administered for minimization of postoperative infection, edema, discomfort, and nausea. Scrubbing and draping of the patient was carried out in a standard fashion. Adrenalin 1/200.000 in normal saline was injected subcutaneously along the incision line to aid in homeostasis and facilitates soft tissue dissection without anesthetizing the marginal branch of the facial nerve.

A submandibular incision for group (I) was carried out to extend $1 \mathrm{~cm}$ beyond the anterior and posterior resection margins. Important landmarks the corner of the mouth and the earlobe must be visible during the procedure. Visualization of these

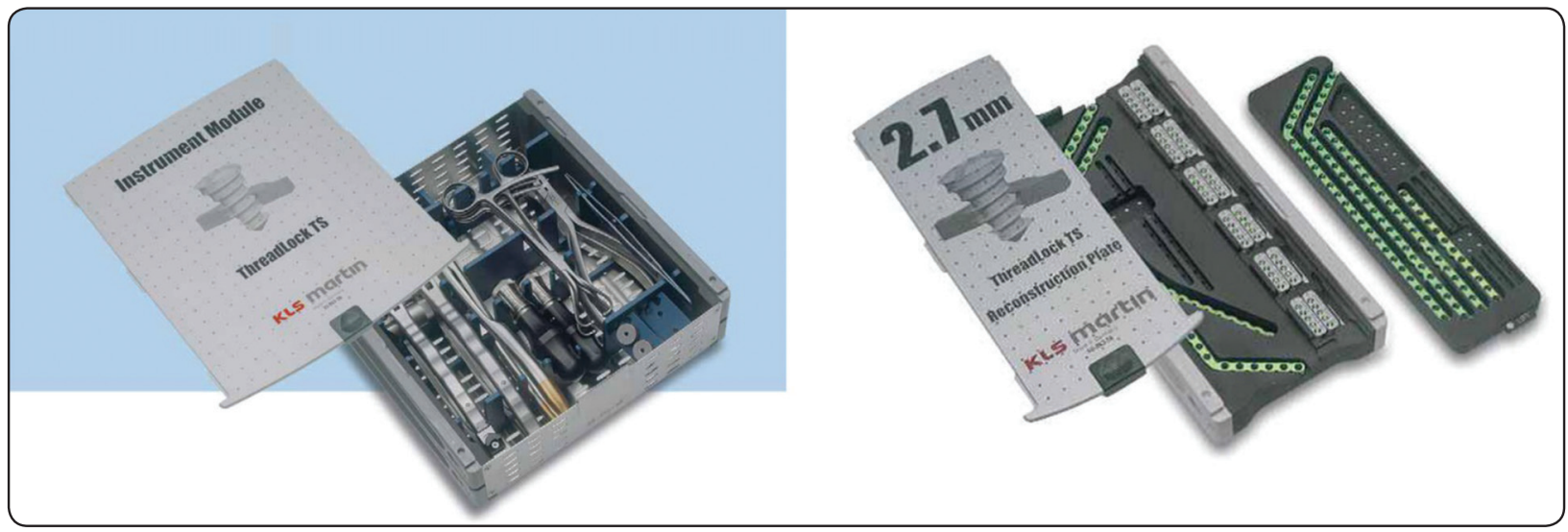

Fig. (3) $2.7 \mathrm{~mm}$ (Thread Lock) reconstruction plate forms and instruments. 
landmarks aids in preservation of the marginal mandibular branch of the facial nerve. Identification of lower lip movement during the dissection will alert surgeon to the proximal relationship of the nerve. Marking the incision is completed with the head in a neutral position. The incision is marked $2 \mathrm{~cm}$ below the inferior border of the mandible and ideally placed in a relaxed skin tension line.

The flap edges were undermined. The platysma muscle was then sharply incised along its inferior edge to be away from the marginal mandibular branch of the facial nerve. Preservation of the nerve is accomplished with a careful dissection through the superficial layer of the deep cervical fascia.

Dissection was completed down to the level of submandibular salivary gland capsule; the facial artery and vein were identified, ligated and cut. The submandibular salivary gland was then retracted medially, the dissection continues toward the mandible, exposing the pterygomasseteric sling posteriorly and periosteum anteriorly. Division of this final layer occurs at the inferior border of the mandible to prevent hemorrhage from the muscle fibers of the masseter. The periosteum was then reflected to expose the bone. In cases were the tumor tissue had perforated the bone cortices, supraperiosteal dissection planes were identified

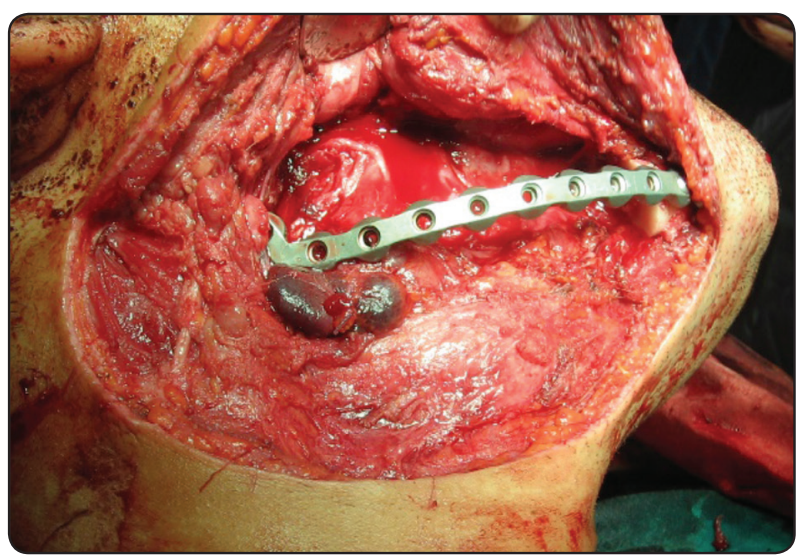

Fig. (4) The locking reconstruction plate secured to the remaining mandibular segments via the traditional wide skin incision in group I cases.
(Fig 4). In group II cases, a submandibular limited incision with length about $3 \mathrm{~cm}$ only was performed (Fig 5).

Intraoral buccal and lingual incisions $2-3 \mathrm{~mm}$ away from the free gingival margins were carried out around the teeth to be included in the resection. The incision was either a full-thickness or a partialthickness one according to the presence or absence of cortical perforations and to the nature of the tumor. The extraoral and intraoral incisions were connected buccally and lingually along their whole lengths.

In group I cases, the plastic template was adapted to the buccal cortex of the mandible to aid in the final adaptation of the reconstruction plate (Fig 6). The osteotomy lines were marked using a long shank surgical tapered fissure (Lindemann) bur.

Temporary intraoperative intermaxillary fixation was used to reestablish proper occlusion before plate placement. The pre-contoured reconstruction plate was then fit in place and fixed to both the proximal and distal segments using the bicortical locking screws, then removed. In group (II) cases, no final adaptation was needed as it was adapted preoperatively on the patient's stereolithographic model (Fig 7).

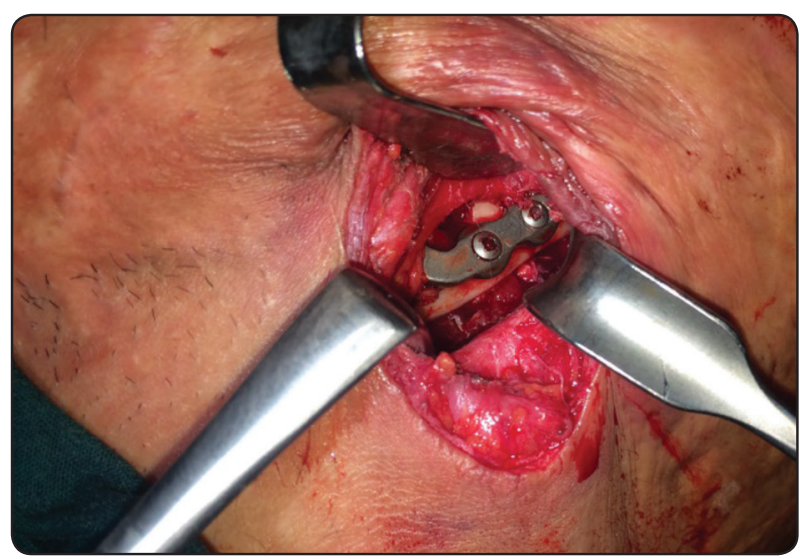

Fig. (5) Intraoperative photograph showing the limited submandibular incision at the left angle to fix the reconstruction plate to the proximal segment (Gp II). 


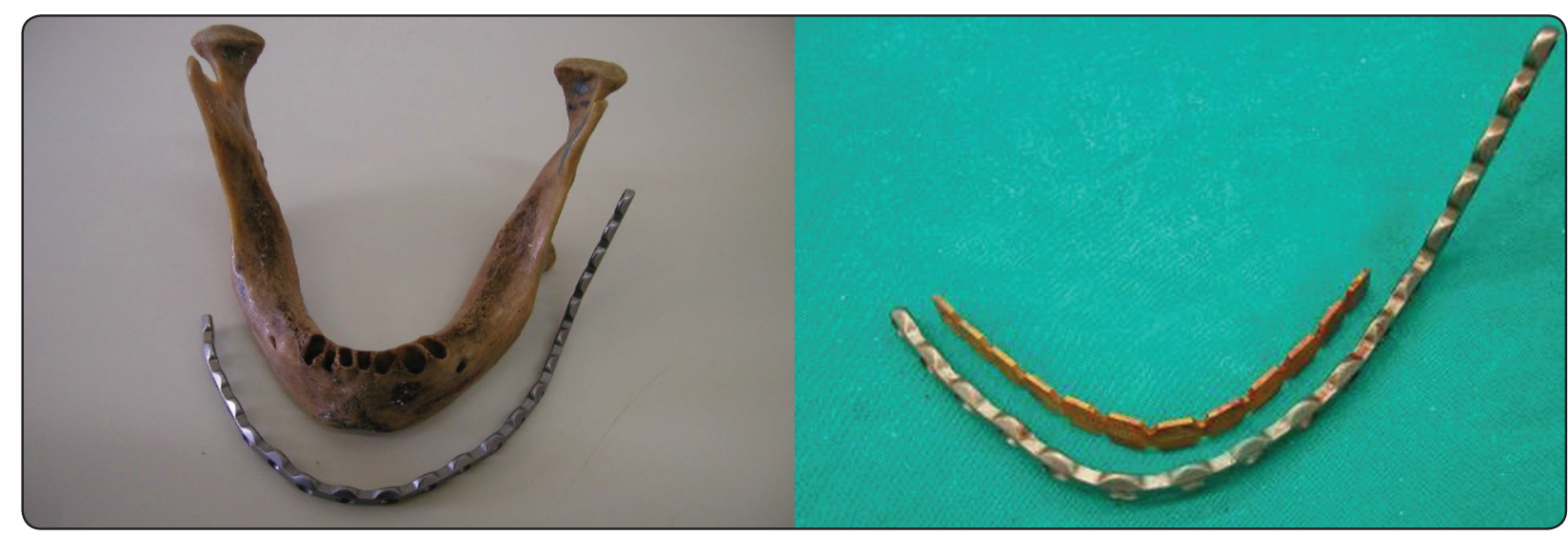

Fig. (6) Plate adaptation in group I cases: Lt; preoperatively on dry mandible, Rt; intraoperatively, final adaptation according to the plastic template.

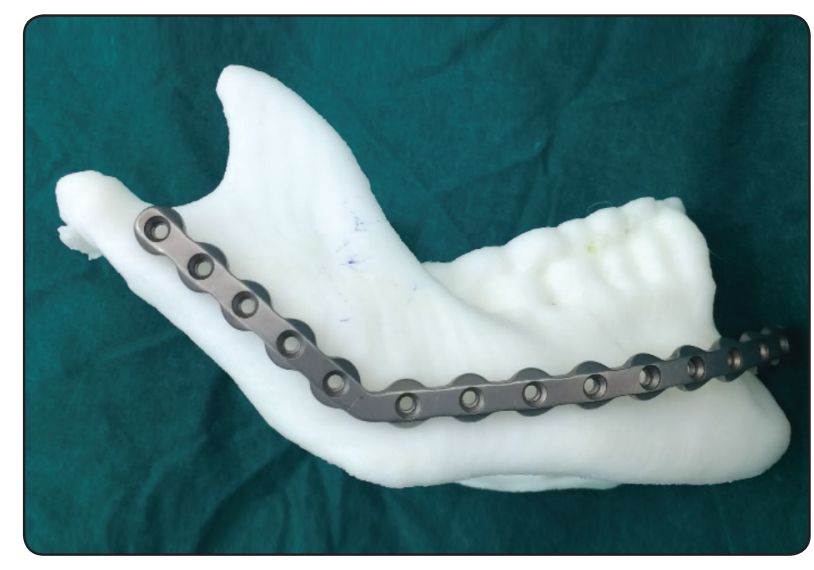

Fig. (7) Preoperative adaptation of the reconstruction plate using the stereolithographic model mirror image of the healthy side (Group II).

The osteotomies completed using giggly saw and the resected segment was removed and the reconstruction plate was then replaced by the aid of screw holes in both the proximal and distal segments.

The intraoral wound was carefully closed in double layers using a combination of interrupted and horizontal mattress resorbable $3 / 0$ sutures. The extraoral surgical site was then copiously irrigated with bovidone iodine and saline/antibiotic mixture before wound closure in layers: periosteum, pterygomasseteric sling (masseter and medial pterygoid), platysma, subcutaneous tissue, and finally skin.
The related surgical events were recorded in both groups for later comparison; the operation time, the time required for plate adjusment and positioning, and the amount of blood loss.

\section{Postoperative care}

Pressure dressings were applied to the external wounds for 24 hours postoperatively. Intermittent ice packs were applied to the areas of surgery during the first day to reduce the post surgical edema, while patients lying on the unoperated sides.

Patients were hospitalized for 72 hours during which they were maintained on a standard regimen of parenteral medication: antibiotics (Ampicillin/ Sulbactam $750 \mathrm{mg}$ vial q6h), non steroidal anti-inflammatory and analgesics (Piroxicam $20 \mathrm{mg}$ ampoule q 12h), freeze-dried proteolytic enzymatic anti-edematous and anti-inflammatory (5mg crystallized and lyophilized chymotrypsin containing 450 units), in addition to mouth wash which was prescribed from the second day after surgery. All patients were instructed to take a soft diet during the healing period.

After discharge, patients were maintained on oral antibiotics (Amoxicillin/Clavulanic acid $625 \mathrm{mg} \mathrm{q} \mathrm{8h}$ ) and analgesics (Piroxicam 20mg dispersible tablets $\mathrm{q} 8 \mathrm{~h}$ ) for 5 more days. The mouth wash was prescribed for 2 more weeks. Patients 
were encouraged to regain normal jaw function. The extraoral sutures were removed 10-14 days postoperatively.

\section{Post-operative follow- up}

Clinically: Patients were followed up weekly during the $1^{\text {st }}$ month, then at the $2^{\text {nd }}, 3^{\text {rd }}$, and $6^{\text {th }}$ months to detect soft tissue healing, pain, infection, screw loosening, reconstruction plate fracture, poor adaptation of the reconstruction plate, malocclusion, TMJ affection, visibility of the skin scar and facial form and symmetry.

\section{Radiographically:}

Panoramic radiographs had been taken immediately, three months and six months postoperatively before autogenous bone grafting. Axial, coronal and three dimensions computed tomography had been taken three months and six months postoperatively before autogenous bone grafting.

The following parameters were assessed: adequacy of the safety margin, accurate plate adaptation, proper angulation, abnormal condyle position, plate over extension beyond the related anatomical regions, and any sign of lesion recurrence especially at the last follow up period.

All data were recorded and statistically analyzed using the statistical package for social science (SPSS version 22). Comparison between the results of the two groups were performed using student t-test and probabilities of 0.05 or less were accepted as significant.

\section{RESULTS}

This study was conducted on sixteen patients suffering from mandibular central benign tumors indicated for segmental mandibular resection. The tumors were mainly in the form of ameloblastoma that was found in 12 patients $(75 \%$; 5 in GpI, 7 in GpII, 9 males, 3 females), followed by ossifying fibroma found in 2 patients $(12.5 \%$; one in each group, 2 males), hemangioma found in only one male patient $(6.25 \%)$ of group I and a hybrid tumor composed of CEOT and AOT found in only one male patient $(6.25 \%)$ of group I (Tables 1,2$)$.

There were 13 (81\%) males (7 in Gp I, 6 in Gp II) and 3 (19\%) females (1 in Gp I, 2 in Gp II) with an age range of 26-54 years and a mean of 39 years. The patient's ages in group I ranged from 26-54 years with a mean of 36.6 years, while in group II ranged from 31-50 with a mean of 41.4 years.

The operation time was markedly reduced and the surgrey was carried out faster in group II (study group) cases with the limited skin incision and the preoperative final bending and contouring of the reconstruction plate on the patient's steriolithographic model. Also there was a signifant decrease in the total blood loss in group II patients (Table 3).

\section{Clinical results (Table 3)}

Soft tissue healing: Primary soft tissue healing of the intraoral incisions had been uneventfully achieved in both groups during the follow up periods. However, healing of the extraoral wounds differs in both groups; as skin scar was noted in all cases of group I until the $6^{\text {th }}$ month of follow up period (Fig 8 ), while it was very limited and inconspicuous in almost all cases of group II (Fig 9).

Pain: Patients in group II suffered less severe pain than group I immediately post-operative and for two to three days. Pain was controlled by intramuscular injection of non steroidal anti-inflammatory and analgesics (Piroxicam $20 \mathrm{mg}$ ampoule q12h).

The pain decreased gradually to the end of the $1^{\text {st }}$ week and also during the $2^{\text {nd }}$ week to become mild pain untill compleyely disappeared by the end of the $3^{\text {rd }}$ week. The pain relief was faster in group II patients. None of the patients of both groups suffered from any distressing pain during the rest of the follow up periods.

Infection: Only one patient of group I (12.5\%) suffered from mild degree of infection after three 
months of the follow up period. It was controlled by antibiotics, non steroidal anti-inflammatory and analgesics. The swelling completely subsided within 1 week but recurred again 1 month later. At the last follow up period an extraoral fistula was noticed. Fistulectomy and plate removal extraorally were done. There was a localized bone resorption around two screws in the lower border of the mandible.

Plate exposure and/or fracture: None of the patients in both groups suffered from plate exposure and/or fracture.

Malocclusion: the same previous patient of group I suffred from malocclusion as a result of plate loosening due to repeated infection. It was corrected

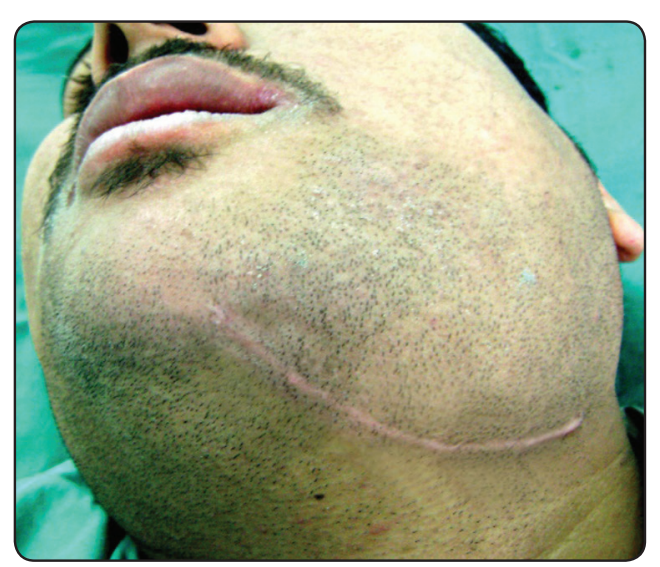

Fig. (8) Postoperative skin incision healing at 6 month with long visible scar line in a patient of group I. by repositioning the plate with newly drilled holes in sound bone and fixation with new screws while the teeth put in proper intermaxillary fixation which is paramount in maintaining good occlusion. Once the plate is refixed with new screws, the occlusion is once again checked and verified for accuracy.

Temporomandibular joint dysfunction: two patients in Gp I showed signs and symptoms of TMJ dysfunction at the $6^{\text {th }}$ month of follow up in the form of pain and clicking at the proximal segemnt site. While none of patients in Gp II showed any sign or symptom of TMJ dysfunction during the follow up recalls.

Good facial form, esthetics and symmetry were noticed in all patients of group II starting from the $2^{\text {nd }}$ postoperative week after resolution of edema and continued through the follow up period with little change (Fig 10). While 5 patients $(62.5 \%)$ in group I (control) were complaining of of slight to moderate facial asymmetry during the same period.

\section{Radiographical results (Table 3)}

Radiographical extension of the pathological bony defects for both groups are illusterated in tables $1 \& 2$.

Postoperative panoramic radiographs: Panoramic radiographs that had been taken immediate, three and six months postoperatively for all patients in both groups showed that adequate safety margins were taken into consideration during the segmental

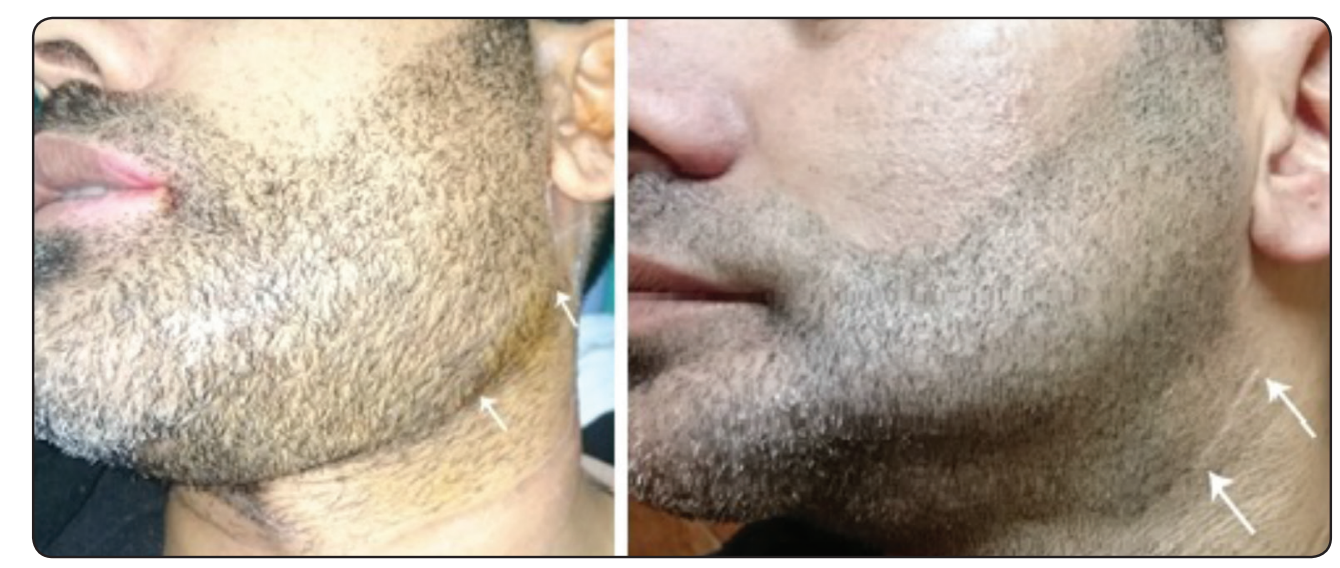

Fig. (9) Postoperative skin incision healing; Lt. at 2 weeks, Rt. at 6 months, with very limited and inconspicuous scar of the submandibular incision at the left angle in a patient of group II (between 2 arrows). 
TABLE (3) Comparison between both groups regarding the operative procedures and postoperative clinical and radiological results at the final follow up period.

\begin{tabular}{|c|c|c|c|c|}
\hline \multicolumn{2}{|l|}{ Findings } & \multirow{2}{*}{$\begin{array}{c}\begin{array}{c}\text { Group I } \\
(\text { Control })\end{array} \\
180\end{array}$} & \multirow{2}{*}{$\begin{array}{c}\text { Group II (Study) } \\
120 \\
\end{array}$} & \multirow{2}{*}{$\begin{array}{c}\begin{array}{c}\text { Statistical Signif } \\
\text { t-test }(\mathrm{P} \leq 0.05)^{*} \\
\leq 0.05^{*}\end{array} \\
\end{array}$} \\
\hline \multirow{3}{*}{$\begin{array}{l}\text { Intraoperative } \\
\text { (Mean) }\end{array}$} & Operation time (min.) & & & \\
\hline & Plate positioning (min.) & 30 & 10 & $\leq 0.05 *$ \\
\hline & Blood loss (ml) & 500 & 200 & $\leq 0.05 *$ \\
\hline \multirow{8}{*}{$\begin{array}{l}\text { Clinical } \\
\text { "Number (\%)" }\end{array}$} & Scar visibility & $8(100.0)$ & $1(12.5)$ & $\leq 0.05 *$ \\
\hline & Pain & 0 & 0 & \\
\hline & Infection & $1(12.5)$ & 0 & $>0.05$ \\
\hline & Plate exposure & 0 & 0 & \\
\hline & Plate loosening & $1(12.5)$ & 0 & $>0.05$ \\
\hline & Malocclusion & $1(12.5)$ & 0 & $>0.05$ \\
\hline & TMJ dysfunction & $2(25.0)$ & 0 & $\leq 0.05 *$ \\
\hline & Facial asymmetry & $5(62.5)$ & 0 & $\leq 0.05 *$ \\
\hline \multirow{5}{*}{$\begin{array}{l}\text { Radiological } \\
\text { "Number (\%)" }\end{array}$} & Recurrence & 0 & 0 & \\
\hline & Accurate plate adaptation & $4(50.0)$ & $8(100.0)$ & $\leq 0.05 *$ \\
\hline & Proper angulation & $4(50.0)$ & $8(100.0)$ & $\leq 0.05 *$ \\
\hline & Abnormal condyle position & 0 & 0 & \\
\hline & Plate over extension & $3(37.5)$ & 0 & $\leq 0.05 *$ \\
\hline
\end{tabular}

* Significant

mandibular resection. Those views also showed the proper position of the residual mandibular segments regarding the occlusion with opposing teeth when present, the relation of the condylar process of proximal segment to the glenoid fossa, the adaptation of the locking reconstruction plate and the restoration of the original contour of the mandible.

Accurate adaptation, contour, form and angulation of the reconstruction plate were noticed in all group II cases (study group) (Fig 11), but only noticed in some of group I cases (control group). In 4 patients (50\%) of group I, there was some form of improper adaptation such as non-symmetrical angle position either higher or lower than the normal side, eccentric angulation with the proximal segment, extension beyond the sigmoid notch of the ramus, and improper contact with lateral mandibular cortex creating a wide gap facilitating screw loosening (Fig 12).

The postoperative axial, coronal and 3-D CT confirmed the findings of OPG regarding plate adaptation and adequate safety margin with healthy and sound bone edges and also clearly confirmed absence of any sign of tumor recurrence (Fig 13).

According to the results presented in table (3) that comparing the two groups at the last follow up period, there was a statistically significant difference in many items under investigation in favor to group II (study group). In spite of occurrence of some clinical events only in group I during the follow up periods such as presence of severe pain, infection, malocclusion and plate loosening, they ultimately had no statistically significant difference between both groups.

The operation time, plate bending and adaptation time, the intraoperative blood loss, scar visibility, TMJ dysfunction, facial asymmetry, accurate plate adaptation, proper plate angulation, and plate over-extension especially in the proximal segment beyond the sigmoid notch, all were with statistically significant differences between both groups with better results always found in group II patients. However, no cases of tumor recurrence, plate exposure, or abnormal condylar position were recorded at the last follow up visit (6 months) in both groups. 


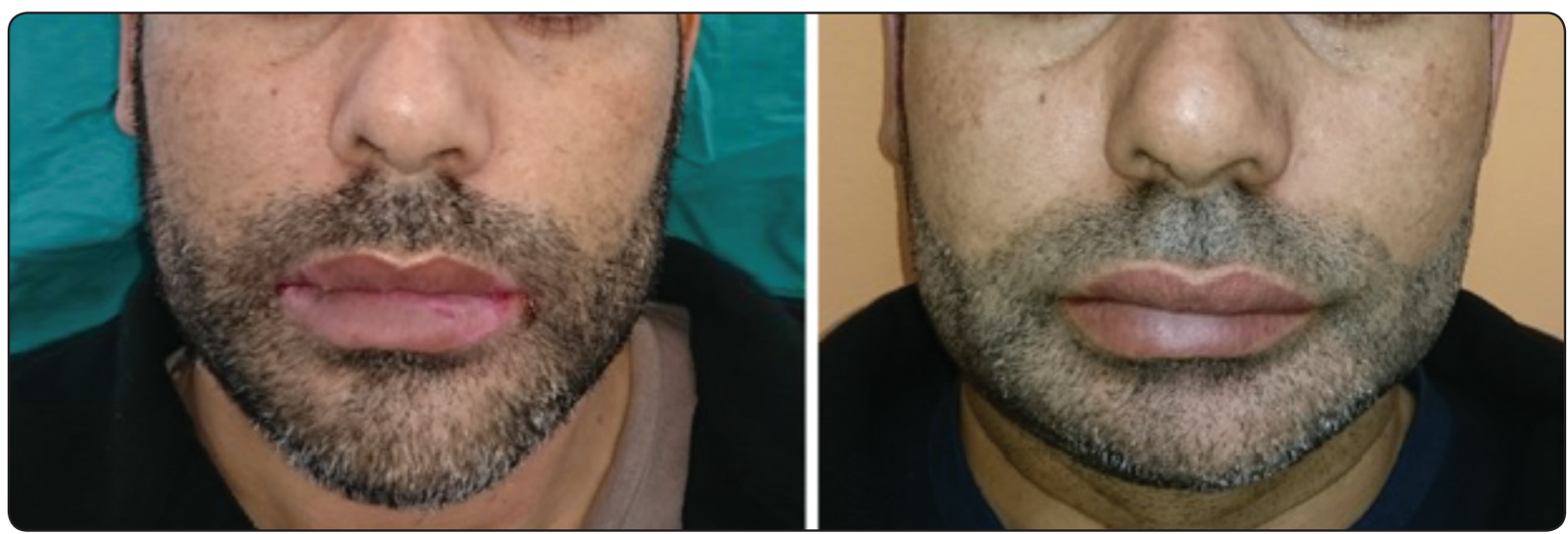

Fig. (10) Postoperative photos; Lt. at 2 weeks, Rt. at 6 months, showing symmetrical face with normal angle shape and contour of Lt side after resection and reconstruction using 3-D model (Gp II patient).
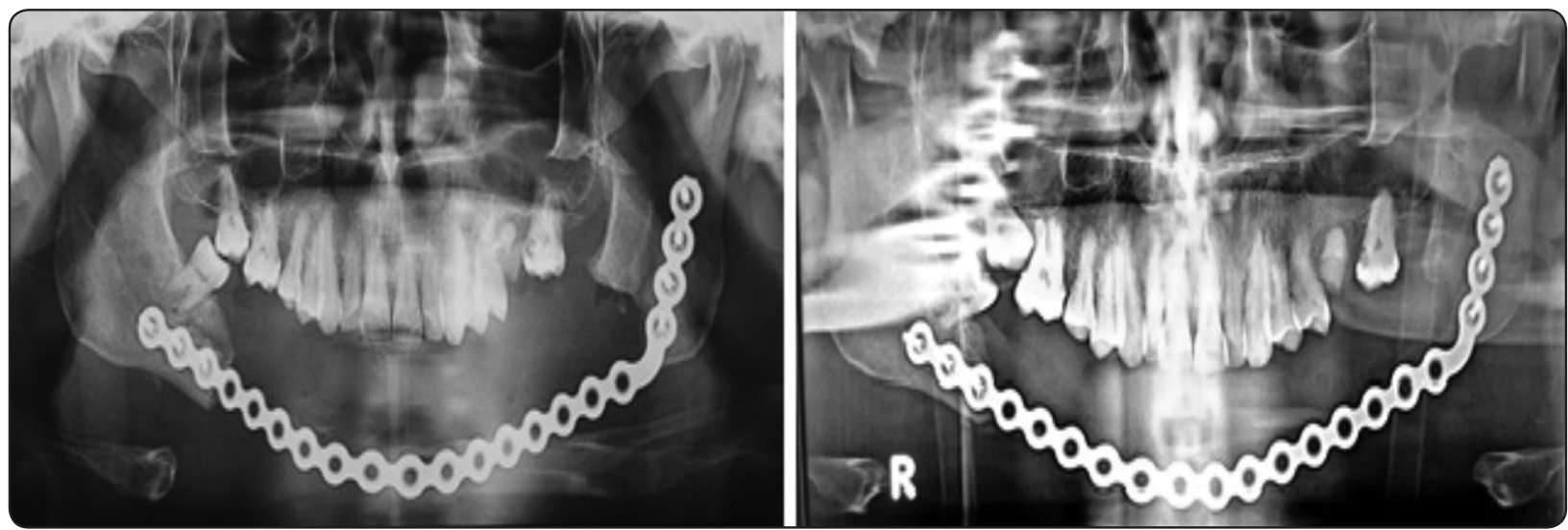

Fig. (11) Postoperative OPG of a patient of group II (study Gp); Lt. at 2 weeks, Rt. at 6 months, showing good adaptation, angulation and contouring of the plate in both the proximal and distal segments, symmetrical bilateral angle position and both condyles in normal relation with the glenoid fossae.

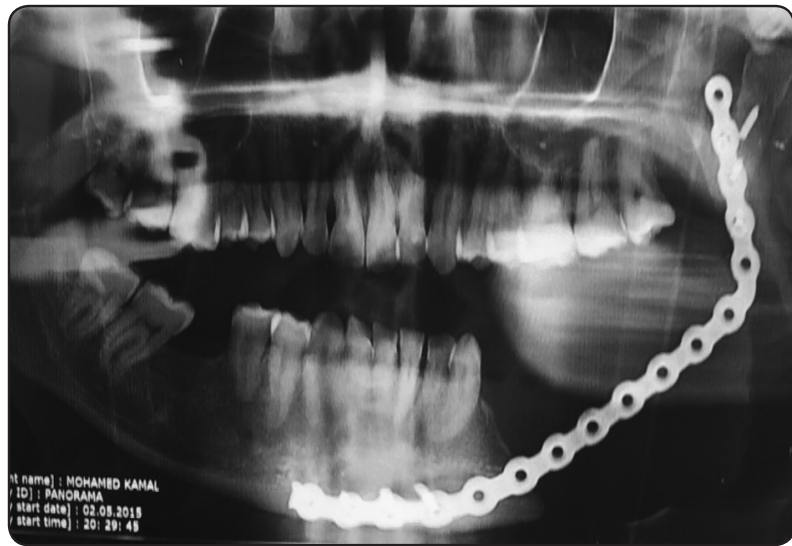

Fig (12) Six months OPG of one of group I patients showing improper adaptaion and angulation of the reconstruction plate. Note the higher angle position, eccentric angulation with the proximal segment, extension beyond the segmoid notch of the ramus, and screw loosening in the distal segmnet.

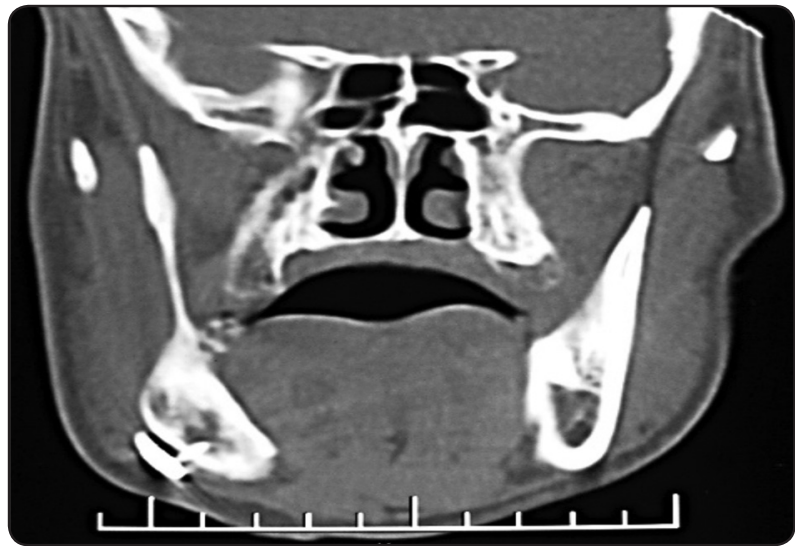

Fig. (13) Six months postoperative coronal CT photoradiograph of a group II patient, showing plate adaptation on the Rt proximal segmnet and adequate safety margin with healthy and sound bone edges of both the proximal and distal segments. 


\section{DISCUSSION}

Restoration of the patient's physical integrity and proper function, normal facial form and harmonious esthetics are the main goals concerning the oral and maxilofacial surgeon facing a case of mandibular resection and reconstruction. The self-perception/ esteem and self-confidence of those patients depend extremely on achieving that goals in a short time which have a great impact on their quality of life, psychological health and quick enrollment in the soceity.

Maurer et al., ${ }^{[15]}$ stated that the main concern of reconstruction has been to restore the approximate anatomical shape of the mandible after resection. Segmental mandibular defect reconstruction is one of the most difficult tasks in maxillo-facial surgery. Due to particularities of each patient and despite a large variety of surgical techniques available for such cases, the choice of the most suitable method remains an important issue.

With recent advances in technology specially with computer simulation and 3-D printing of hardwares, the use of steriolithographic mandibular models of the patients mandibles greatly facilitates the procedures in reconstructive surgery. This modern technique enabled us to adapt the reconstruction plate totally and finally preoperativelly with maximum accuracey and also to properly place it in a good anatomic position via a very limited submandubular skin incision that was not suitable to be used before, this technique is represented by group II (study) patients in this study.

The advantages of using the steriolithogarphic models in this study come in parallel with the results of a recent research performed by Marchetti ${ }^{[16]}$ who designed reconstructive bony plates using the 3-D original external cortical bone as a template in reproducing the ideal mandibular contour and ensuring the native morphology of the reconstructed mandible. He found this reconstructive technique to be a valid method to accurately restore the preoperative morphological situation of the native mandible, giving the surgeon advantages compared with conventional procedures in terms of better functional and aesthetic results, more procedural control, reduced surgical time and reduced number of complications.

This is also in accordance with a previous study carried out by Hannen ${ }^{[17]}$ and reported that the prebent reconstruction plates upon stereolithographic models could be easily fit in place intraoperative even without the use of any form of intermaxillary fixation. This allowed for more accurate positioning of the edentulous proximal segment and the mandibular condylar process in the gleniod fossa resulting in excellent postoperative function in terms of occlusion and lack of pain in the temporomandibular joint.

In the same context Chow and Cheung [18] stated that it is widely accepted that utilization of 3-D models offers many distinct advantages for improved patient care. One can easily design soft tissue incisions, surgical resection margins, assess bony defects for grafting not only adaptation and pre-bending of reconstruction plates.

The newly adopted technique in group II patients of this study was found to have several advantages over the traditionally used method in group I patients; it provides a quiker surgery with little intraoperative complications such as blood loss, limited soft tissue incision and manipulation that greatly reduces the postoperative edema, pain and discomfort, better postoperative facial esthetics resulted from inconspicuous skin scar and nice symmetrical fcial contour, rapid healing period and limited fibrosis which provide excellent vascularized recepient soft tissue bed that greatly gurantee a successful secondary bone grafting procedures.

Samson et al., ${ }^{[19]}$ used the 3-D printing technology and 3-D designing software to design a patient specific reconstruction implant for resected mandibular segments and the surgery was planned 
using anatomic models and virtual surgery much before performing the actual surgical procedure. They reported that the used method increasingly reduced the surgical time, the surgical complications and provided for improved form, function and esthetics of the patient.

In mentioning the advantages of using 3-D models in their research, Curcio et al., ${ }^{[20]}$ showed that the use of 3-D models has proven to greatly decrease surgical operating time, decrease time under general anesthesia, and decrease wound exposure time. The cumulative effect has produced better patient care, improved colleague communication and more predictable and accurate surgical results. The model also enables the surgeon to determine the required length of the plate as well as length and number of screws before surgery.

The delayed concept of bone grafting for a minimum of 6 months after immediate placement of the reconstruction plate is employed in this study and also is the ploicy of our deparment in managing those cases to avoid contamination of the graft by exposure to the oral environment and to provide enough healthy tissue coverage and completely vascularized soft tissue bed.

Mathew et al., ${ }^{[21]}$ are in agreement with this surgical concept as they stated that the goals of reconstructing the segmental mandibular defects are to reconstitute its three-dimensional shape, preserve or restore lower facial contour, provide a prosthetic platform, and maintain or re-create occlusal relationships and oral continence. The problems of salivary contamination and inadequate soft tissue coverage might lead to loss of bone graft and encourage the idea of delayed mandibular reconstruction.

Also the locking plate screw system used in this study was proven to have certain advantages over conventional plates and screws: less screw loosening, greater stability and less alteration in osseous or occlusal relationship upon screw tightening if the plate was properly adapted preoperatively. ${ }^{[22]}$

Lindqvist et al., ${ }^{[23]}$ showed that bone resorption can lead to plate instability and screw loosening, necessitating its removal. This matches our findings and management of one patient in group I in this study.

Screw loosening and displacement often result from one of the following errors: (1) inadequate number of screws placed, (2) screw placement into nonviable bone, or (3) poor drilling technique. Placing an inadequate number of screws in the proximal and distal bone segments can cause undue stress on the screws, causing them to dislodge. Three properly placed, bicortical screws may be acceptable if the reconstruction plate is being used as an interim reconstruction device for a short period (6 months). Bicortical screw placement is always preferable to monocortical screw fixation. Bicortical screws can usually be placed if the plate is properly positioned and contoured. ${ }^{24]}$

We followed the same technique of proper plate placement mentioned by Michael et al., ${ }^{[24]}$ in this study by using at least 3 bicortical screws on each side of the residual bony segment which resulted in a good success rate $(93.7 \%)$ in both groups and $(100 \%)$ in group II regarding the plate stability and integrity in a 6 month period.

It is worhty to mention that after finishing this study and getting its results, the policy of our departement is shifted to use this technique employed in group II patients in all cases indicated for mandibular reconstruction and became the routine surgical planning and management.

\section{CONCLUSION}

Based on the results of this study, it was found that the use of the patient's 3-D steriolithographic model for virtual surgical planning for segmental mandibular resection has several advantages over the traditionally used method. It improves 
reconstruction of form and function, decreases operating room time and complications and enhances the capability to perform more accurate surgical procedures. Also the limited skin incision used in association with this method resulted in less soft tissue manipulation that significantly reduces the postoperative edema, pain and discomfort, improves facial esthetics with inconspicuous skin scar and nice symmetrical facial contour, and heals with limited fibrosis which provides excellent vascularized recepient bed that greatly gurantee a successful secondary bone grafting procedures.

\section{REFERENCES}

1. Homer M. Single stage mandibular reconstruction using clavicle with SCM pedicle flap. The Philip J Otolaryngol Head Neck Surg 2004; 19: 175-179.

2. Carlson E, Marx R. Part II. Mandibular reconstruction using cancellous cellular bone grafts. J Oral Maxillofac Surg 1996; 54: 889-97.

3. Jewer D, Boyd, Manktelow R, et al. Orofacial and mandibular reconstruction with iliac crest free flap: A review of 60 cases and a new method of classification. Plast Reconstr Surg 1989; 84: 391.

4. Schliephake H, Neukam F, Schmelzeisen R, et al. Long term quality of life after ablative intraoral tumor surgery. $\mathrm{J}$ Craniomaxillofac Surg 1995; 23:243-9.

5. Rogers S, Fisher S, Woolgar J. A review of quality of life assessment in oral cancer. Int J Oral Maxillofac Surg 1999; 28:99-117.

6. Soderholm A, Hallikainen D, Lindqvist C. Radiological follow- up of bone transplants for bridging mandibular continuity defects. Oral Surg Med Pathol 1992; 73:253261 .

7. Militsakh $\mathrm{O}$, Wallace $\mathrm{D}$, Kriet $\mathrm{J}$ et al. Use of the $2.0 \mathrm{~mm}$ locking reconstruction plate in primary oromandibular reconstruction after composite resection. Otolaryngol Head Neck Surg 2004; 131(5): 660-5.

8. Coletti D, Ord R, Liu X. Mandibular reconstruction and second generation locking reconstruction plates: Outcome of 110 patients. Int. J. Oral Maxillofac. Surg 2009; 38: 960-963.
9. Lawson W, Loscalzo L, Beak S, et a1. Experience with immediate and delayed mandibular reconstruction. Laryngoscope 1982; 92: 5-10.

10. Shaw RJ, Kanatas AN, Lowe D, et al. Comparison of miniplates and reconstruction plates in mandibular reconstruction. Head Neck 2004; 26(5):456-63.

11. Ung F, Rocco JW, Deschler DG. Temporary intraoperative external fixation in mandibular reconstruction. Laryngoscope 2002; 112(9):1569-73.

12. Edwards SP. Computer-assisted craniomaxillofacial surgery. Oral Maxillofac Surg Clin North Am 2010; 22(1):117-34.

13. Kennady MC, Tucker MR, Lester GE, et al. Stress shielding effect of rigid internal fixation plates on mandibular bone grafts. A photon absorption densitometry and quantitative computerized tomographic evaluation. Int J Oral Maxillofac Surg 1989; 18(5):307-10.

14. Wong T. , Fang J, Chung C, Huang J, Lee J. Comparison of two methods of making surgical models for correction of facial asymmetry. J Oral Maxillofac Surg 2005; 63:200208.

15. Maurer P, Eckert A, Kriwalsky M, Schubert J. Scope and limitations of methods of mandibular reconstruction: a long -term follow up. Br J Oral Maxillofac Surg 2010; 48 (2): $100-4$.

16. Marchetti C. Mandibular reconstruction: our experience with the use of computer-aided design/computer-aided manufacturing technology. Int J Oral Maxillofac Surg 2017; 46 (1): 34. DOI: http://dx.doi.org/10.1016/j.ijom. 2017.02 .125

17. Hannen E. Recreating the original contour in tumor deformed mandibles for plate adapting, Int J Oral Maxillofac Surg 2006; 35: 183-5.

18. Chow L, Cheung L.The usefulness of stereomodels in maxillofacial surgical management. J Oral Maxillofac Surg 2007; 65:2260-2268

19. Samson J, Nesan J, Karthik B, Venkatakrishnan CJ. Use of 3D-digital technologies to design patient specific implants in mandibular reconstruction. Int J Oral Maxillofac Surg 2015; 44 (1): e133-e134.

20. Curcio R, Perin GL, Chilvarquer I, Borri ML, Ajzen S. Use of models in surgical predictability of oral rehabilitations. Acta Cir Bras 2007;22(5):387-95. 
21. Mathew B, Adam S, Daniel B, et al. Contemporary reconstruction of the mandible. Oral Oncology 2010; 46: 1-76.

22. Chana J, Chang Y, Wei F, et al. Segmental mandibulectomy and immediate free fibula osteoseptocutaneous flap reconstruction with endosteal implants: an ideal treatment method for mandibular ameloblastoma, Plast Reconstr Surg 2004; 113: 80-7.
23. Lindqvist C, Söderholm A, Salo A, et al. A comparative study on four screw-plate locking systems in sheep: a clinical and radiological study. Int J Oral Maxillofac Surg 2001; 30 (2): 160-166.

24. Michael J. Zak, Andrew J. Lerrick. Fixation of mandibular flaps and grafts: Avoiding complication. Copyright (C) 2000 by W.B. Saunders Company doi 2000; 10.1053/ otot. 2000.8062 